\title{
Journal of Surgery
}

[Jurnalul de Chirurgie]

\section{Rapidly Progressive Osteolysis of the Femoral Head Following An Acetabular Fracture - Case Report}

Ovidiu Alexa, Radu loan Malancea, Bogdan Puha*, Dragos Popescu and Bogdan Veliceasa

Department of Orthopedics and Traumatology, "St. Spiridon" Emergency Hospital, lasi, Romania

\begin{abstract}
Posttraumatic osteolysis is a rare complication of fractures. We present a case of massive, rapidly progressive osteolysis of the femoral head following a fracture of the acetabulum. A 45 years old male patient suffered a transverse acetabular fracture that involved the posterior wall. Through a Kocher-Langenbeck approach we performed open reduction and internal fixation of the fracture with two reconstruction plates. Postoperative radiologic control showed acceptable fracture reduction. At 45 days after surgery, a routine X-ray control was performed and a massive osteolysis involving about $50 \%$ of the femoral head was noticed. Three months after the surgery, quasi-total disappearance of the femoral head with superior dislocation of the remaining blunt was observed. Massive osteolysis of the femoral head is a new entity of post-traumatic osteoarthritis described in a small number of patients which should not be confused with aseptic necrosis or rapidly progressive osteoarthritis.
\end{abstract}

Keywords: Posttraumatic osteolysis; Acetabular fracture; Femoral head osteolysis

\section{Introduction}

In 1838, posttraumatic osteolysis as a complication of a humerus fracture [1] was described for the first time by Halaby. This complication usually occurs in young patients, several months or even years after the traumatic incident and it usually is self-limiting. It can be located anywhere in the skeleton, but the most frequent site is in the distal third of the clavicle [2-6].

The aim of this paper was to present a case of massive, rapidly progressive, osteolysis of the femoral head following a fracture of the acetabulum.

\section{Case Presentation}

A 45 years old male, was the victim of a car accident and suffered multiple trauma for which he was admitted in the emergency room in June 2015. Based on conventional radiographs as shown in Figure 1 and CT scans as shown in Figure 2, the patient was diagnosed with a transverse and posterior wall acetabular fracture according to the Judet and Letournel classification [7]. Also, he was diagnosed with C7-C9 rib fractures, head trauma and multiple contusions (Figures 1 and 2).

Through a Kocher-Langenbeck approach, we performed open reduction and internal fixation of the fracture with two reconstruction plates. Postoperative radiologic control showed acceptable fracture reduction according to the Matta criteria [8] (Figure 3).

Immediate postoperative evolution was favourable. The following day after surgery, the drainage was removed and motor rehabilitation was initiated in bed. From the third day, the patient started to walk with crutches without weight barring on the operated limb. Blood tests did not show pathological changes in the immediate postoperative period. Stitches were removed 21 days after surgery with a favourable local evolution.

Six weeks after surgery, a routine X-ray control was performed and we noticed a massive osteolysis involving about $50 \%$ of the femoral head. However, the patient did not report significant pain when mobilizing his right hip. CT exam showed the extent of the osteolysis (Figure 4). Three months after surgery, X-ray and CT images showed quasi-total disappearance of the femoral head with superior dislocation of the remaining blunt (Figure 5). At four months, total hip arthroplasty was performed using a Burch-Schneider ring for acetabular component fixation (Figures 4-6).

\section{Discussion}

Aseptic necrosis of the femoral head (AVN) is a common complication of acetabular fractures. It occurs usually six months two years postoperatively. In our case the destruction of the femoral head was almost totally without passing the tipical stages of AVN. The particularity of the presented case lies in the short time elapsed since the moment of the acetabular fracture to the appearance of massive osteolysis of the femoral head (6 weeks).

Rapidly progressive osteoarthritis is a rare, but possible complication of traumatic fractures. It was first described by Lequesne [9] as joint space shrinking by more than $2 \mathrm{~mm}$ per year. It is occasionally associated with massive destruction of the femoral head and/or acetabulum, usually after six to twelve months [10]. In 2017, Seo [11] described a series of fifteen cases of massive osteolysis of the femoral head (MOFH) which does not appear to be an entity of avascular necrosis or rapidly progressive osteoarthritis, but a distinctive variant of post-traumatic osteolysis. The pathogenesis of this complication is not clearly explained and must be differentiated from aseptic necrosis of the femoral head. Considering the evolution and massive destruction of the femoral head, we believe that our case can be included in this new entity - "massive osteolysis of the femoral head" (MOFH).

*Corresponding author: Bogdan Puha, Department of Orthopedics and Traumatology, "St. Spiridon" Emergency Hospital, Iași, Romania, Tel: +40 (0) 7222234 18; E-mail: puhab@yahoo.com

Received March 30, 2017; Accepted April 15, 2017; Published April 22, 2017

Citation: Alexa O, Malancea RI, Puha B, Popescu D, Veliceasa B. Rapidly Progressive Osteolysis of the Femoral Head Following an Acetabular Fracture - Case Report Journal of Surgery [Jurnalul de chirurgie]. 2017; 13(2): 81-84 DOI: 10.7438/1584-9341 13-2-7

Copyright: (c) 2017 Alexa O, et al. This is an open-access article distributed under the terms of the Creative Commons Attribution License, which permits unrestricted use, distribution, and reproduction in any medium, provided the original author and source are credited. 


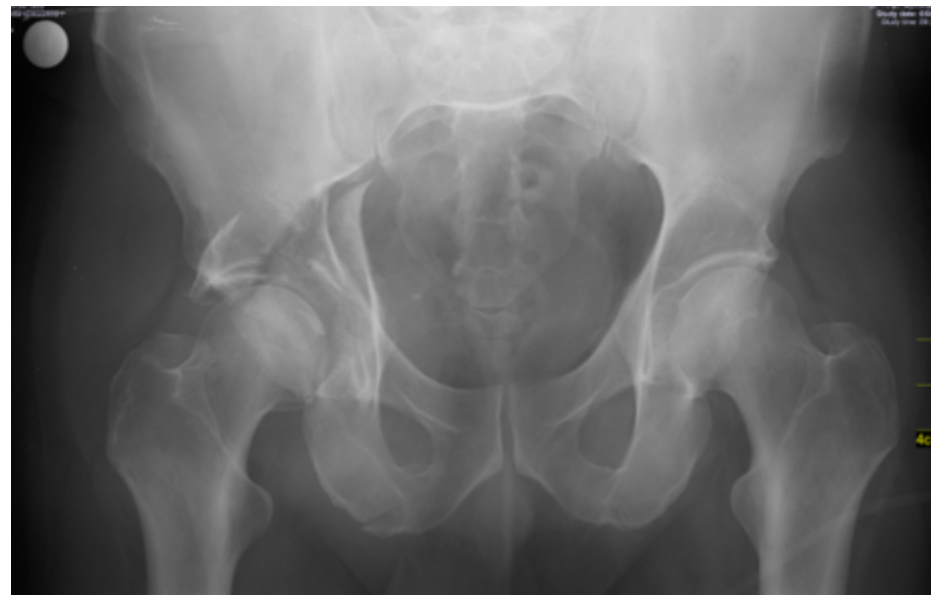

Figure 1: Pelvic X-ray, AP view: transverse fracture of the right acetabulum with displacement.
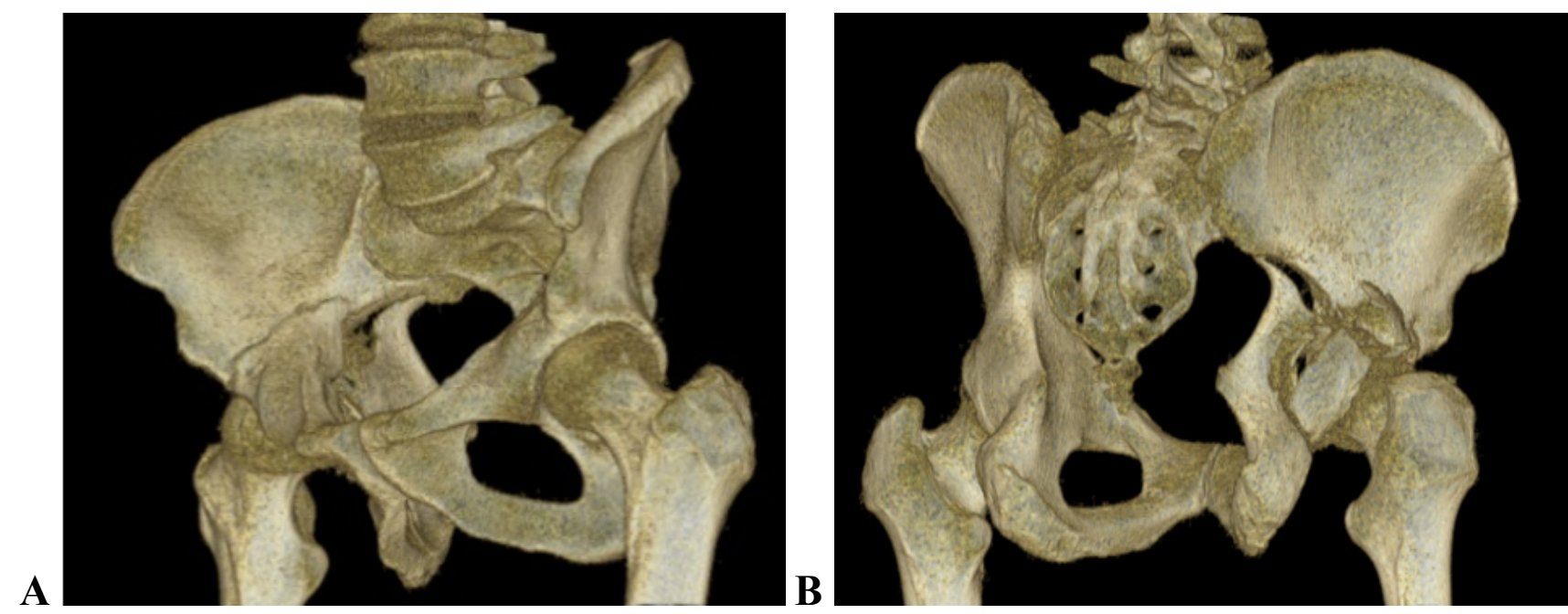

Figure 2: Preoperative CT scan - 3D reconstruction showing the transverse fracture of the right acetabulum with displacement (A) and the associated cominutive posterior wall fracture $(\mathrm{B})$.

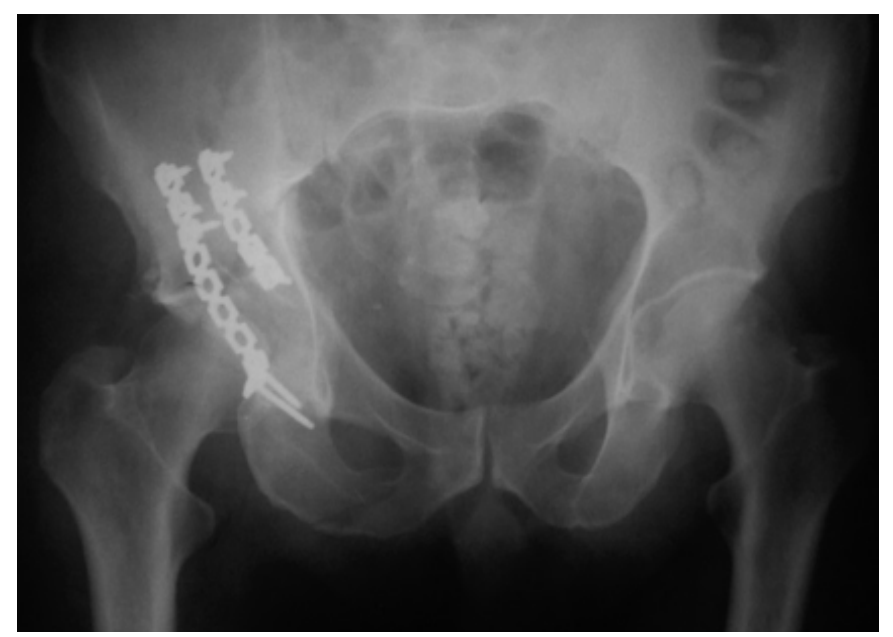

Figure 3: Third day postoperative X-ray (AP view): acceptable fracture reduction and osteosynthesis with two reconstruction plates with $2 / 2$ and respectively $3 / 2$ screws on the posterior column.

\section{Conclusion}

Massive osteolysis of the femoral head (MOFH) is a new entity of post-traumatic osteoarthritis described in a small number of patients which should not be confused with aseptic necrosis or rapidly progressive osteoarthritis. 


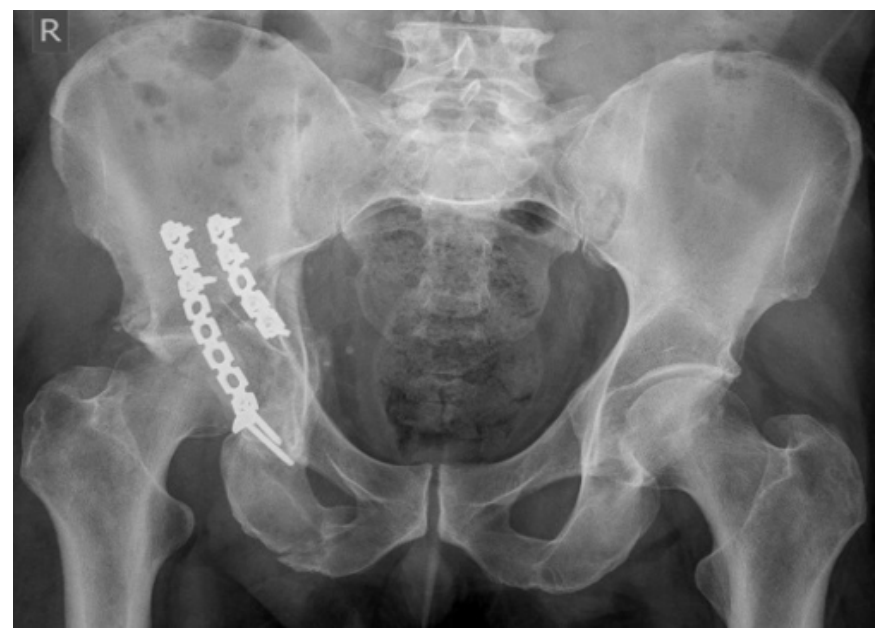

Figure 4: 45 days postoperative x-ray (AP view): callus formation into the fracture site, but associate osteolysis of more than $50 \%$ of the femoral head.
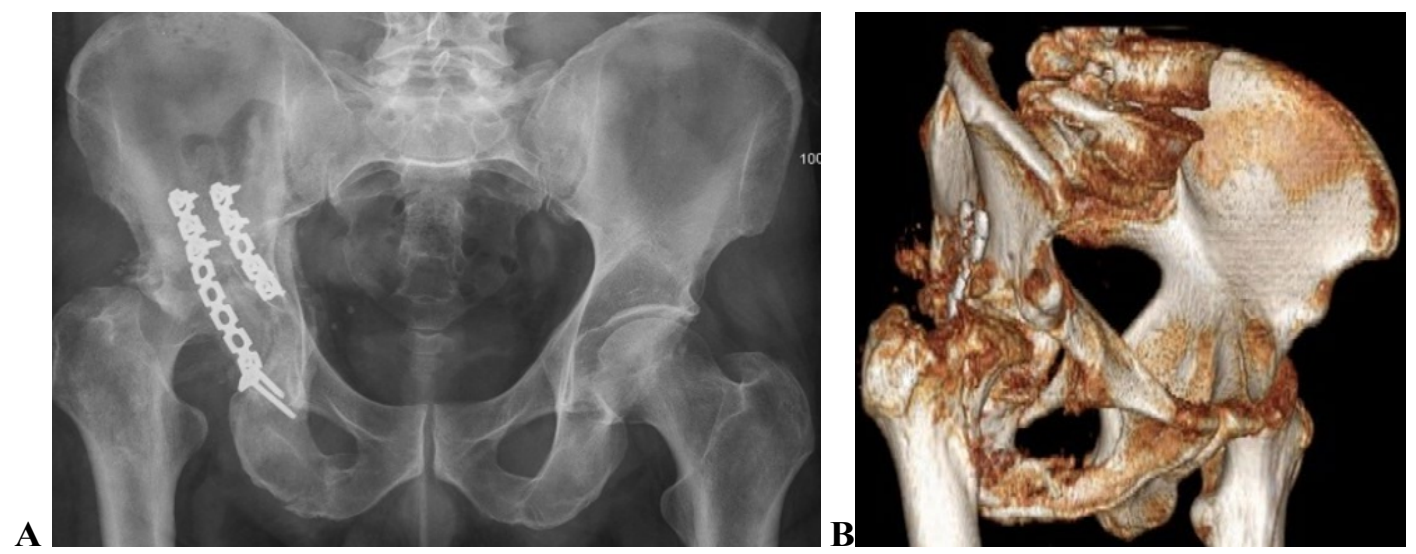

Figure 5: Three months postoperative x-ray (A) and 3D CT scan (B): quasi-total disappearance of the femoral head with superior dislocation of the remaining blunt.

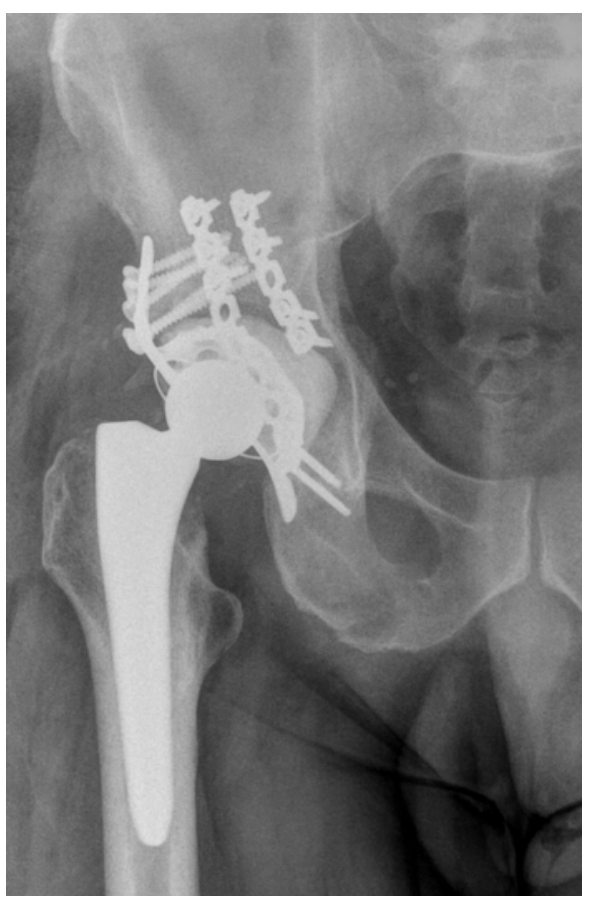

Figure 6: Four-month postoperative right hip x-ray: total hip arthroplasty with a Burch-Schneider reinforcing acetabular ring.

\section{Conflict of Interest}

Authors have no conflict of interest to disclose.

\section{References}

1. Halaby FA, Disalvo El (1965) Osteolysis: A complication of trauma. Report of 2 cases. Am J Roentgenol Radium Ther Nucl Med 94: 591-594.

2. Jacobs P (1964) Post-traumatic osteolysis of the outer end of the clavicle. $J$ Bone Joint Surg Br 46: 705-707.

3. Asano H, Mimori K, Shinomiya K (2002) A case of post-traumatic osteolysis of the distal clavicle: Histologic lesion of the acromion. J Shoulder Elbow Surg 11: 182-187.

4. Hall FM, Goldberg RP, Kasdon EJ, Glick H (1984) Post-traumatic osteolysis of the pubic bone simulating a malignant lesion. J Bone Joint Surg Am 66: $121-126$.

5. Roback DL (1980) Posttraumatic osteolysis of the femoral neck. Am J Roentgenol 134: 1243-1244.

6. Puylaert D, Nuyts R, Ramael M, Verstreken J (1995) Rapidly progressive destruction of the hip. Case report and review of the literature. Acta Orthop Belg 61: 312-314.

7. Judet R, Judet J, Letournel E. (1996) Fractures of the acetabulum Classification and surgical approaches for open reduction: Preliminary report. J Bone Joint Surg Am 46: 1615-1646.

8. Matta JM (1996) Fractures of the acetabulum: accuracy of reduction and clinical results in patients managed operatively within three weeks after the injury. J Bone Joint Surg Am 78: 1632-1645.

9. Lequesne M (1993) Rapidly progressing destructive diseases of the hip. Ann Radiol 36: 62-64. 
10. Batra S, Batra M, McMurtrie A, Sinha AK (2008) Rapidly destructive osteoarthritis of the hip joint: A case series. J Orthop Surg Res 3: 3.
11. Seo GS, Dieudonne G, Mooney SA, Monu JU (2017) Unexplained "massive osteolysis of femoral head" (MOFH) after acetabular fracture: occurrence and suggested patho-etiology. Acta Radiol 58: 710-718. 